\title{
Oral Health Status Among Hearing and Speech Impaired Children of Karachi, Pakistan
}

\author{
Marium Azfar ${ }^{1}$ \\ BDS, MPH \\ Imran Khan ${ }^{2}$ \\ BDS, MSc \\ Sameer Quershi ${ }^{3}$ \\ Nighat $\mathbf{Z i a}^{4}$ \\ Khadijah Abid $^{5}$ \\ BDS, MSc \\ BDS, MSc \\ BSC, MSc
}

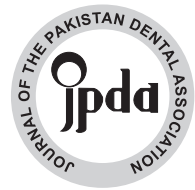

OBJECTIVE: To evaluate dental status of children with hearing and speech impairment of Karachi Pakistan. METHODOLOGY: This cross sectional study was conducted in Karachi, Pakistan for a period of 6 month among 106 children with hearing and speech impairment aged 5-15 years of either gender attending Deaf Reach School. After taking informed consent the subjects were examined for oral health status. Dental caries was assessed by using DMFT index and Oral hygiene status was assessed by using oral hygiene index simplified (OHIS). The data were analyzed using SPSS version 23.

RESULTS: The overall caries prevalence in the study population was 51\% with an overall mean DMFT score of 2.08 $( \pm 2.97)$. Out of 106 hearing and speech impaired children, majority had good hygiene status $(48.1 \%), 46.2 \%$ had fair hygiene status and only $5.7 \%$ had poor hygiene status with overall mean OHI-S score of $1.45 \pm 1.01$.

CONCLUSION: A high prevalence of dental caries was observed among hearing and speech impaired children. KEYWORDS: Dental caries, DMFT, Oral health, Oral hygiene status, deaf, hearing and speech impaired children. HOW TO CITE: Azfar M, Khan I, Qureshi S, Zia N, Abid K. Oral health status among hearing and speech impaired children of Karachi, Pakistan. J Pak Dent Assoc 2018;27(4):181-85.

DOI: https://doi.org/10.25301/JPDA.274.181

Received: 08 May 2018, Accepted: 14 June 2018

\section{INTRODUCTION}

$\mathrm{D}$ ental care is noted to be the most common issue $\&$ unmet need among disabled children. Disabled children are at greater risk of poorer oral health due to other major disease such as frequent oral infections, moderate to severe malocclusion, periodontal disease \& craniofacial birth defects. ${ }^{1}$ The oral needs among them may be compromised to due limited access to facilities of oral health care, neglect from parents or care takers, socioeconomic status or communication barriers. ${ }^{2}$ Therefore, the disabled children appear to have more worsen oral health as

1. Associate Professor, Department of Preventive \& community dentistry, Sindh Institute of oral health sciences, Jinnah Sindh Medical University.

2. Assistant Professor, Department of Preventive \& community dentistry, Sindh Institute of oral health sciences, Jinnah Sindh Medical University.

3. Assistant Professor, Department of Prosthodontics, Fatima Jinnah Dental college.

4. Assistant Professor, Department of Preventive \& community dentistry, Sindh Institute of oral health sciences, Jinnah Sindh Medical University.

5. Senior Bio-Statistitcian, Department of Research Evalution Unit, College of Physicians \& Surgeons Pakistan.

Corresponding author: "Khadijah Abid" < khadijahabid@gmail.com > compared to general population. ${ }^{3}$ Judicial says in London, "Fit for the future" suggested that Oral wellbeing of disabled children ought to be raised to the level of that provided for normal children. ${ }^{4}$

Deafness is the common disability in childhood. Almost two to three children per 1000 have some level of permanent congenital hearing loss. ${ }^{5}$ According to $\mathrm{WHO}$ estimate there are 360 million people globally with hearing impaired, among them $9 \%$ of these are children under the age of 15 . The prevalence of hearing loss disability among children is very high in Asia Pacific, South Asia, and Sub-Saharan Africa. The leading cause hearing impaired among children is chronic otitis media. ${ }^{6}$ In Pakistan, it is estimated about 1.6 per 1000 persons have bilateral hearing loss and $70 \%$ increase is due consanguineous families. ${ }^{7}$ A survey conducted at the rural area of Pakistan showed total hearing impaired as $7.9 \% .{ }^{8}$

Children with hearing \& speech impairment have greatest barrier of communication. They cannot understand or cooperate with dental healthcare providers easily. Literature has reported an increased level of dental caries in these 
sensory impaired children. ${ }^{9,10}$ Hence, there is no current data available on the oral status of deaf and dumb children of Sindh, Pakistan. Therefore, the present study was designed to provide primary data for development and planning of regional or national oral health programs for these children.

\section{METHODOLOGY}

It was a cross-sectional study conducted at the Deaf Reach School Karachi, Pakistan and duration of study was 6 months. The sample size of 106 participants was obtained by using open epi online sample size calculator. The statistics considered for sample size estimation was dental caries as $30.74 \%{ }^{11}$, margin of error as $8.8 \%$ and $95 \%$ confidence level. The non-probability purposive sampling technique was employed. All children of 5-15 years of either gender having speech \& hearing impairment were included in the study. Children exhibiting other forms of sensory disorders or those affected by mental and physical disabilities along with speech and hearing loss were excluded from the study.

Before check-ups the Pakistan Sign Language (PSL) training workshop was conducted for the two examiners. ${ }^{12}$ The aim of this workshop was to familiarize the examiners with deaf culture and basic sign language that is used to communicate with deaf children.

Informed consent was taken from school admin and parents of the children to participate in the study. All the parents were informed regarding the study protocol during their monthly visit to the school and consent was obtained. The clinical examination was carried according to World Health Organization (WHO) techniques ${ }^{13}$ in the OPD of Integrated Occupational Health Services (IOHS) by the two examiner with experience of 3 years. Examiners were calibrated and validated by doing examination on 20 subjects. The inter examiner reliability was checked using Kappa statistics and it was found to be $83 \%$. The children were then examined for oral status by making them sit on the upright chair in adequate light using autoclaved instruments; plain mouth mirror and WHO probe. Caps, gloves, masks and gauze were used in accordance with infection control guidelines. Dental caries was evaluated by using DMFT (decayed, missing, and filled teeth) index. ${ }^{14}$ The DMFT score $=0$ was labelled as "caries-free" \& DMFT score $>0$ as "caries present". Oral hygiene was evaluated by using the simplified oral hygiene index (OHI-S) introduced by Green and Vermillion. ${ }^{15} \mathrm{OIH}-\mathrm{S}$ score was labelled for oral cleanliness as "good" for score between 0.1-1.2, "fair" between 1.3-3.0 and "poor" between 3.1-6.0. ${ }^{16}$ Each examination took about 10-15minutes.

The demographic information such age, gender, weight
$\&$ height of the children was recorded. BMI of each children was calculated by using the formula BMI =weight $/$ height $^{\text {t2 }}$ $\left(\mathrm{kg} / \mathrm{m}^{2}\right)$. Other related information regarding previous dental visits, frequency of tooth brushing, material used for brushing $\&$ food preferences was obtained under the supervision of school interpreters.

The data was entered into database, using Epi Info Version 3.6.1 by the researcher. To reduce data entry errors, check codes were incorporated into the database and the data was cleaned to ensure consistency of responses. For questions that were unanswered or blank responses during data entry were treated as missing variables.

Data analysis was carried out using the SPSS Version 23 . Normality of the data was checked by using KolmogrovSmirnov test. Frequencies and percentages were calculated for all the qualitative variables. Mean \& SD were calculated for all the quantitative variables. Chi-square was applied where appropriate. The confidence level was considered as $95 \%$ and $\mathrm{P}$-value $<0.05$ was taken as statistically significant.

\section{RESULTS}

The study sample was consisted of 106 children with mean age as $12.88 \pm 2.59$ years. Out of 106,64 were males and 42 were females. The mean BMI of the children was reported as $20.10 \pm 4.09 \mathrm{~kg} / \mathrm{m} 2$. Majority of the children had never visited the dentist (57.5\%). About $59.4 \%$ of them brushed once daily, $28.3 \%$ of them brushed twice a day, $7.5 \%$ of them brushed after every meal and only $4.7 \%$ of them brushed less than one time. Majority of the subjects (91.5\%) were using toothpaste to clean their teeth, tooth power was used by $5.7 \%$ \& no material was used by $2.8 \%$ of the children. Regarding eating habits, majority of children $(91.5 \%)$ were consumer of confectionaries, flavored sweetened milk was consumed by $73.6 \% \& 83 \%$ of the children were habitual consumers of sweetened juices. (Table 1)

The overall caries prevalence in the study population was $68.9 \%$ with an overall mean DMFT score of $7.58 \pm 2.62$. According to dentition status, sixteen children had dental caries in primary teeth, whereas 57 children had dental caries in permanent teeth. None of the children had missing primary teeth due to caries or other reasons, filled teeth with or with no decay. Two children had permanent teeth missing due to caries, none had missing teeth due to other reasons, two had permanent filled with no decay, and one child had permanent filled with decay. Out of 106 hearing and speech impaired children, majority had good hygiene status (48.1\%), 46.2\% had fair hygiene status and only $5.7 \%$ had poor hygiene status with overall mean OHI-S score of $1.45 \pm 1.01$. (Table 2) 
Table 1: Baseline characteristics of whole cohort:

\begin{tabular}{|c|c|}
\hline VARIABLES & STATISTICS \\
\hline Age in years & $12.88 \pm 2.59$ \\
\hline Gender & $64(60.4 \%)$ \\
Male (\%) & $42(39.6 \%)$ \\
Female (\%) & $20.10 \pm 4.09$ \\
\hline BMI (kg/m2) & \\
\hline Dental Visits & $61(57.5 \%)$ \\
Haven't visit (\%) & $45(42.4 \%)$ \\
\hline Visited at least once (\%) & \\
\hline Brushing Frequency & $63(59.4 \%)$ \\
Once a day (\%) & $30(28.3 \%)$ \\
Twice a day (\%) & $8(7.5 \%)$ \\
After every meal (\%) & $5(4.7 \%)$ \\
\hline Less than once a day (\%) & \\
\hline Material Used for Brushing & $97(91.5 \%)$ \\
Toothpaste & $6(5.7 \%)$ \\
Tooth powder & $3(2.8 \%)$ \\
\hline No material & $78(73.6 \%)$ \\
\hline Eating \& drinking habits & $88(83 \%)$ \\
Sweet milk consumption & $97(91.5 \%)$ \\
Consumption of juices & \\
Consumption of confectionaries & \\
\hline &
\end{tabular}

Table 2: Dental caries and oral health status

\begin{tabular}{|c|c|}
\hline \multicolumn{2}{|c|}{ Dental Health Status } \\
\hline DMFT index & $7.58 \pm 8.62$ \\
\hline Dental caries & \\
Caries Free (\%) & $33(31.1 \%)$ \\
Caries Present (\%) & $73(68.9 \%)$ \\
\hline Debris index & $0.92 \pm 0.56$ \\
\hline Calculus index & $0.54 \pm 0.62$ \\
\hline OHI-S index & $1.45 \pm 1.01$ \\
\hline Oral Hygiene Status & \\
Good Oral Hygiene & $51(48.1 \%)$ \\
Fair Oral Hygiene & $49(46.2 \%)$ \\
Poor Oral Hygiene & $6(5.7 \%)$ \\
\hline
\end{tabular}

Table 3: Age and gender wise distribution of dental caries and oral hygiene status

\begin{tabular}{|c|c|c|c|c|c|c|c|}
\hline & \multicolumn{2}{|c|}{ Dental Caries } & P-value & \multicolumn{3}{|c|}{ Oral Hygiene Status } & P-value \\
\hline Age Groups & Present & Absent & \multirow[b]{3}{*}{0.511} & Good & Fair & Poor & \multirow[b]{3}{*}{0.493} \\
\hline $5-10$ years & $15(75 \%)$ & $5(25 \%)$ & & $12(60 \%)$ & $7(35 \%)$ & $\mathrm{I}(5 \%)$ & \\
\hline $11-15$ years & $58(67.4 \%)$ & $28(32.6 \%)$ & & $39(45,3 \%)$ & $42(48.8 \%)$ & $5(5.8 \%)$ & \\
\hline \multicolumn{8}{|l|}{ Gender } \\
\hline Male & $43(67.2 \%)$ & $21(32.8 \%)$ & \multirow[b]{2}{*}{0.645} & $30(46.9 \%)$ & $31(48 \%)$ & $3(4.7 \%)$ & \multirow[b]{2}{*}{0.782} \\
\hline Female & $30(71.4 \%)$ & $12(28.6 \%)$ & & $21(50 \%)$ & $18(42.9 \%)$ & $3(7.1 \%)$ & \\
\hline
\end{tabular}

The age and gender wise distribution of dental caries and oral hygiene status has been shown in Table 3. The stratification of dental caries was done with respect to brushing frequency, eating habits, dental visits and obesity
Table 4: Association of dental caries with other variables

\begin{tabular}{|c|c|c|c|}
\hline \multirow{2}{*}{ Variables } & \multicolumn{2}{|c|}{ Dental Caries } & \multirow{2}{*}{ P-value } \\
\cline { 2 - 3 } & Yes & No & \\
\hline Brushing Frequency & & & \\
Once a day & $43(58.9 \%)$ & $20(60.6 \%)$ & \\
Twice & $18(24.7 \%)$ & $12(36.4 \%)$ & \\
After every meal & $7(9.6 \%)$ & $1(3.0 \%)$ & \\
Less than once a day & $5(6.8 \%)$ & $0(0.0 \%)$ & 0.198 \\
\hline Eating Habits & & & \\
Sweet Milk & $54(74.0 \%)$ & $24(72.7 \%)$ & 0.893 \\
Juices & $61(83.6 \%)$ & $27(81.8 \%)$ & 0.825 \\
Confectionaries & $65(89.0 \%)$ & $32(97.0 \%)$ & 0.175 \\
\hline Dental Visits & & & \\
Haven't visit (\%) & $37(50.6 \%)$ & $24(72.7 \%)$ & \\
Visited at least once & $36(49.3 \%)$ & $9(27.2 \%)$ & 0.095 \\
\hline Obese(BMI=>27.5 $\left.\mathbf{~ k g} / \mathbf{m}^{2}\right)$ & & & \\
Yes & $70(95.9 \%)$ & $30(90.9 \%)$ & \\
No & $3(4.1 \%)$ & $3(9.1 \%)$ & 0.304 \\
\hline
\end{tabular}

by using chi-square test, hence the relationship was found as statistically insignificant $(\mathrm{p}>0.05)$. (Table 4$)$

\section{DISCUSSION}

Our study shows that majority of the hearing and speech impaired children had never visited to a dentist for any treatment or check-up. The similar proportions was presented in previous literature of the disabled children. ${ }^{3,17,18}$ The reason for not visiting the dentist could be due less priority of parents/caretakers regarding importance of dental health, lack of communication and low socio-economic status. ${ }^{19,20}$

In the present study, only $4.7 \%$ of the children didn't use to brush their teeth whereas majority of the children brushed their teeth once daily (59.4\%) followed by $28.3 \%$ of the children brushed their teeth twice a day and $7.5 \%$ of the children use to rinsed their mouth after every meal. In the present study we also observed that majority of the children used toothpaste \& tooth brush as cleaning materials. The similar findings was observed in the study by Prashanth ST et al. at Banglore among disabled children, which showed $62.35 \%$ of the children use to brushed their teeth only once in the morning $\& 37.65 \%$ of the children responded that they use to brushed twice a day $\& 98.82 \%$ of the children clean their teeth with toothbrush. ${ }^{21}$

In the present study most of the children prefered confectionaries $91.5 \%$, about $83 \%$ consumed juices and $73.6 \%$ consumed sweetened milk. In the study conducted by Folakemi OA found that most of the pupils $(60 \%)$ prefered biscuits, sweets and softdrinks. ${ }^{22}$ Children eating habits could be potentially influenced by parent's social and envirnomental behaviours such as the use of food as rewards and the withholding of food as punishment. ${ }^{23}$ The study stated that less consumption and lower intake of sweets is very important 
especially for down synodrome patients since they are unable to maintain proper oral hygiene. ${ }^{22}$

In the present study, mean DMFT was very high and reported as $7.58 \pm 2.62$ and dental caries was prevalent among $68.9 \%$ of children. With increase in age range prevalence of dental caries was also increased and male was prominently affected by caries. Similar findings was observed in the study by Suma G et al. which showed higher prevalence of dental caries among the 11-15 years old children and majority of the males were affected by the caries. ${ }^{3}$

In the present study, most of the children had good hygiene status (48.1\%). The dissimilar findings was observed in previous literature where frequency of poor oral hygiene was observed as high among disable children. ${ }^{24,25}$ In the present study, we observed that with increase in age of the children the good hygiene practice has also increased. However, the frequency of good oral hygiene was high among males as compared to females.

In the present study we have also assessed the relationship of dental caries with brushing frequency, eating habits, dental visits and obesity. We found that dental caries predominantly affecting the children who brushed their teeth once a day, children who consumed confectionaries/juices/sweet milk, children who had never visited dentist and children who were obese. Hence these variables can be considered as potential risk factors for poor dental health among children with hearing and speech impairment.

\section{CONCLUSION}

A high prevalence of dental caries was observed among hearing and speech impaired children There is a high need for an epidemiological survey followed by the comprehensive dental care programs for children with hearing speech impairment, as well as efforts should be taken to encourage and promote parents of these children to improve their oral health.

\section{CONFLICT OF INTEREST}

None to declare

\section{REFERENCES}

1. Rocha LL, de Lima Saintrain MV, Vieira-Meyer APGF. Access to dental public services by disabled persons. BMC oral health. 2015; $15(1): 35$.

https://doi.org/10.1186/s12903-015-0022-x

2. Nahar SG, Hossain MA, Howlader MBU, Ahmed A. Oral health status of disabled children. Bangladesh Med Res Counc Bull. 2010;36(2):61-3.
3. Suma G, Das UM, Akshatha B. Dentition status and oral health practice among hearing and speech-impaired children: A cross-sectional study. Int J Clin Pediatr Dent. 2011;4(2):105.

4. Court S. Fit for the Future: Report of the Committee on Child Health Services. HMSO London; 1976.

5. hadha NK, Chadha R, James AL. Why are children deaf? Paediatr Child Health. 2009;19(10):441-6.

https://doi.org/10.1016/j.paed.2009.05.001

6. Organization WH. WHO global estimates on prevalence of hearing loss, mortality and burden of diseases and prevention of blindness and deafness. Geneva: WHO; 2012.

7. Yan D, Kannan-Sundhari A, Vishwanath S, Qing J, Mittal R, Kameswaran M, et al. The genetic basis of nonsyndromic hearing loss in Indian and Pakistani populations. Genet Test Mol Biomarkers. 2015;19(9):512-27.

https://doi.org/10.1089/gtmb.2015.0023

8. Elahi MM, Elahi F, Elahi A, Elahi SB. Paediatric hearing loss in rural Pakistan. J Otolaryngol Head Neck Surg. 1998;27(6):348.

9. Shaw L, Maclaurin ET, Foster TD. Dental study of handicapped children attending special schools in Birmingham, UK. Community Dent Oral Epidemiol. 1986;14(1):24-7.

https://doi.org/10.1111/j.1600-0528.1986.tb01488.x

10. Prashant G, Chandu G, Shafiulla M. Dental caries experience among 6-18 years old blind children of residential school, Bangalore, Karnataka. J Indian Assoc Public Health Dentist. 2005;5(6):18-21.

11. Yadav O, Shavi G, Panwar M, Rana S, Gupta R. Prevalence of dental caries and periodontal disease in deaf and mute children attending special schools in Jaipur city, Rajasthan. J Dent Health Oral Disord Ther. 2017;7(4):00252.

https://doi.org/10.15406/jdhodt.2017.07.00252

12. Iman DN, Zuberi S. Pakistan Sign Language-A Synopsis. http://www.academia.edu/2708088/Pakistan_Sign_Language__A_Synopsis. Accessed 24 oct 2018.

13. Organization WH. Oral health surveys: basic methods: WHO; 2013.

14. Larmas M. Has dental caries prevalence some connection with caries index values in adults? Caries Res. 2010;44(1):81-4. https://doi.org/10.1159/000279327

15. Greene JG, Vermillion JR. The simplified oral hygiene index. J Am Dent Assoc. 1964;68(1):7-13.

https://doi.org/10.14219/jada.archive.1964.0034

16. Al-Mutawa S, Shyama M, Al-Duwairi Y, Soparkar P. Oral hygiene status of Kuwaiti schoolchildren. East Mediterr Health J. 2011;17(5):387-391.

https://doi.org/10.26719/2011.17.5.387

17. Oredugba FA. Use of oral health care services and oral findings 
in children with special needs in Lagos, Nigeria. Spec Care Dentist. 2006;26(2):59-65.

https://doi.org/10.1111/j.1754-4505.2006.tb01511.x

18. Kumar S, Dagli RJ, Mathur A, Jain M, Duraiswamy P, Kulkarni $\mathrm{S}$. Oral hygiene status in relation to sociodemographic factors of children and adults who are hearing impaired, attending a special school. Spec Care Dentist. 2008;28(6):258-64.

https://doi.org/10.1111/j.1754-4505.2008.00049.x

19. Ubido J, Huntington J, Warburton D. Inequalities in access to healthcare faced by women who are deaf. Health Soc Care Community. 2002;10(4):247-53.

https://doi.org/10.1046/j.1365-2524.2002.00365.x

20. Gillcrist JA, Brumley DE, Blackford JU. Community socioeconomic status and children's dental health. J Am Dent Assoc. 2001;132(2): 216-22.

https://doi.org/10.14219/jada.archive.2001.0158

21. Gillcrist JA, Brumley DE, Blackford JU. Community socioeconomic status and children's dental health. J Am Dent Assoc. 2001;132(2): 216-22.

https://doi.org/10.4103/0970-4388.84680

22. Oredugba FA. Oral health care knowledge and practices of a group of deaf adolescents in Lagos, Nigeria. J Public Health Dent. 2004;64(2):118-20.

https://doi.org/10.1111/j.1752-7325.2004.tb02739.x

23. Dennison BA. Fruit juice consumption by infants and children: a review. J Am Coll Nutr. 1996;15(sup5):4S-11S.

24. Pool D. Dental care for the handicapped adolescent. Int Dent J. 1982;32(2):194-202.

25. Mann J, Wolnerman JS, Lavie G, Carlin Y, Garfunkel AA. Periodontal treatment needs and oral hygiene for institutionalized individuais with handicapping conditions. Spec Care Dentist. 1984;4(4):173-6.

https://doi.org/10.1111/j.1754-4505.1984.tb00358.x 